\title{
Visualization, Comprehension of Metacognitive Strategy, and The Importance Of An Evaluation Framework
}

\author{
Siti Sarah Fitriani \\ Universitas Syiah Kuala \\ Banda Aceh, Indonesia
}

\author{
Iskandar Abdul Samad \\ Universitas Syiah Kuala \\ Banda Aceh, Indonesia
}

\begin{abstract}
Visualization metacognitive strategy, either internal or external, has been used for decades to help students comprehend a reading text. Their comprehension is usually evaluated using a reading comprehension test. Without this test, literacy teachers can actually evaluate students' comprehension by analyzing students' visual representations that they draw as a summary of a text they read. To do this, the teachers need a framework as the guideline to relate students' drawing to their comprehension. This paper proposes a framework necessary to evaluate students' comprehension of a reading text that they transform into a visual representation. The aspects in the framework are created based on the literature on visual literacy and genre-based literacy pedagogy. An example of the analysis is also provided in this paper.
\end{abstract}

\section{Keywords—visualization; comprehension; framework}

\section{INTRODUCTION}

Visualization is one of the strategies in metacognition. It divided into two types: internal and external. The internal visualisation refers to mental imagery a reader creates in his/her mind while trying to get the meaning of a text he/she is reading, which is invisible [1]. When this imagery transformed into a drawing, it was called an external visualisation, which is visible; and this can be drawn for example in the form of images, charts or diagrams depending on the types of text being read [2].

For few decades, this strategy has been widely tested and used to promote readers' comprehension to a text; either academic or non-academic. Some researchers argue that weak comprehenders are unable to use visualisation [3], while proficient readers automatically employ this strategy [4]. It suggested that when a user can visualise a text, he/she is reading, he/she is also able to get the meaning conveyed by the text. Put simply; visualisation strategy fosters critical literacy [5].

Recent studies have also indicated the advantage of the approach in reading [5]-[7]. Most of these past and current researchers introduced visualisation to read non-academic texts. Regarding the visualisation types, they mostly focused on the internal one; their participants were encouraged to create mental imagery in a reading process.
Literacy teachers can evaluate students' understanding of meaning in a particular text by analysing visual representations drawn by the students. While most studies promote visualisation by comprehension, references in the literature that can be used as frameworks to relate visual representation and comprehension are still insufficient. Thus, through this paper, we propose a framework that can help teachers understand their students' comprehension presented in their drawings.

\section{RESEARCH METHOD}

This research used literature study to determine indicators in evaluating the student's comprehension. The subject of this study is the literature related to visualisation, comprehension, and the importance of an evaluation framework.

\section{RESULT AND DISCUSSION}

Metacognition consists of metacognitive knowledge and metacognitive experiences or regulation this metacognitive refers to attitudes of the person or people which are processes that can be applied to control cognitive activities and achieve cognitive goals. Metacognitive knowledge refers to the acquisition of knowledge about cognitive processes, the knowledge that can be used to control cognitive processes [8]. Moreover, he believes that metacognition as thinking about thinking. The Metacognition is the ability to think where the object of thinking is the process of thinking that happens to yourself.

Meanwhile, Margaret W. Matlin in his book entitled Cognition, states: "Metacognition is our knowledge, awareness, and control of our cognitive process" [9]. Metacognition, according to Matlin, is knowledge, awareness, and control of the cognitive processes that happen to oneself.

According to Wellman that metacognition as a form of cognition, or two or more thought processes that involve control of the cognitive activity. Therefore, metacognition can be said to be a person's thinking about his thinking or someone's cognition about his cognition [10].

According to the definition above in general, metacognition is thinking about thinking. While specifically, he cites the definition of metacognition made by Taylor, 
namely "Recognition of what is already known, along with a true understanding of what learning tasks, knowledge, and skills are required in learning, and then combined with the ability to draw the right conclusions on how to apply one's strategic knowledge to a certain condition, as well execute it efficiently and reliably "[8].

Strategies that can be done by teachers or lecturers in developing metacognition of learners through learning and learning activities are as follows [11]:

1) Helping learners in developing learning strategies by:

a) Encourage the learner to monitor the learning and thinking process.

b) Guiding learners in developing effective learning strategies.

c) Ask the learner to make predictions about the information that will appear or be presented next based on what they have read or the tracker.

d) Guiding learners to develop the habit of asking questions.

e) Show the learner how the technique of transferring knowledge, attitudes, values, skills from one situation to another.

2) Guiding learners in developing good learners habits through:

a) Development of self-managing habit: The development of self-managing habits can be done by: (1) identifying the learning style that best suits oneself (visual, auditive, kinesthetic, deductive, or inductive); (2) monitoring and improving learning skills (reading, writing, listening, managing time, and problem-solving); (3) making use of a varied learning environment (in class with lectures, discussions, assignments, laboratory practices, group learning, etc.).

b) Developing the habit of positive thinking: Positive thinking habits are developed by: (1) improving selfconfidence and self-esteem and (2) identifying learning goals and enjoying learning activities.

c) Develop habits for thinking hierarchically: Habituious habits of thinking are developed by: (1) making decisions and solving problems and (2) integrating and creating relationships of new concepts.

d) Developing the habit of asking questions: Questioning habits are developed by (1) identifying key ideas or concepts and supporting evidence; (2) generate interest and motivation; and (3) focusing attention and memory.

The development of learner metacognition can also be done with simple activities then leading to more complicated ones.

\section{A. Genre-based Literacy Pedagogy}

Literacy practice in classrooms encourages students to read different genres such as narrative, descriptive, explanation, recount and procedure [12] with comprehension as the golden goal [13]. The genre is staged and goal oriented [14]; each of its types presents different goals, stages, and language features. This has suggested that when reading different text types, students also learn different things.

For example, when they read an explanation text, they read some processes related to natural phenomena. A text with a topic of 'water cycle' will inform the process of natural water production occurred in our nature. To compare a procedural text also presents some processes/steps, but these are to inform the procedure of doing a thing, for example, the procedure of fixing a flat tyre or making a cake. As a consequence, when students read different text types by employing visualization, they create different formations of visualisation. These formations, if they are transformed into visual representations, can indicate students' comprehension of the texts. This can be seen from the aspects included in the genre. A genre-specific drawing informs viewers the goal, stages and language features of a text. A visual representation specific to a type indicates students' comprehension to a text. Therefore, style aspects are suggested to be involved in the framework of analysis.

A genre-specific drawing informs viewers the goal, stages and language features of a text. A visual representation specific to a genre indicates students' comprehension to a text. Therefore, genre aspects are suggested to be involved in the framework of analysis.

\section{B. Visual Literacy}

A visual representation drawn by students is considered a multimodal text. This text combines images and language [15]. A drawing produced in a reading process can be regarded as a summary of a text being read to represent the information that students comprehend, which is done differently to the way word-only texts do [16]. For literacy teachers to understand multimodal texts (in this case is students' drawings) and at the same time evaluate comprehension, visual literacy skill is important to be developed. This includes the understanding of the organization of information, the relationship between images and language, and the types of image which are presented in a visual representation.

Kress and Leeuwen suggest that the use of vectors as connectors indicates the relationship between participants involved in an image [17]. The appropriate use of connectors in a drawing presents sequential information. The use of frames, circles, and vectors that may appear in a drawing needs to be analyzed in the order of information in a text being read. We can evaluate whether students understand the flow of information of a text they read from their visual representations by looking at the order of the images and language using these sequencing tools. When they can arrange them by following the order of the text, they are considered understand.

Regarding image-language relation, Unsworth and Chan specify this into two basic types [18], [19]: elaboration and extension. Elaboration occurs when an image specifies or describes language or vice versa. The elaboration is divided into two; the first one is an equivalence. This type is indicated when both image and language convey a similar message. Exposition is the other type of elaboration which takes place 
to reformulate meaning to image or language. The second type of image-language relationship, which is the extension, also has two sub-types; these are augmentation and distribution. Augmentation is also called additive, which appears when an image or language adds meaning to the other. Distribution exists when an image and language are pairing to develop information sequentially.

For the framework that we develop, we use the term 'coreferential' for equivalence, 'additive' for augmentation, and 'symbiotic' for distribution. It is necessary to see these relationships in students' visual representation to evaluate how images and language complement each other to present information. The information that students present in their drawings demonstrate their understanding of a text they visualised.

From the discussions of genre-based pedagogy and visual literacy, we conclude a framework to evaluate students' comprehension which is shown in the following tables 1 .

TABLE I. FRAMEWORK TO EVALUATE STUDENT'S COMPREHENSION

\begin{tabular}{|c|c|c|c|}
\hline \multicolumn{3}{|c|}{ The order of information } & Check \\
\hline \multirow{4}{*}{ Sequent } & \multirow{2}{*}{$\begin{array}{l}\text { Matches } \\
\text { sequencing }\end{array}$} & Yes & \\
\hline & & Partially & \\
\hline & \multirow{2}{*}{$\begin{array}{lr}\text { Dynamic } & \text { with } \\
\text { appropriate } & \text { text } \\
\text { organizing } & \\
\text { image/language } & \\
\end{array}$} & Accurate & \\
\hline & & Partially & \\
\hline \multicolumn{3}{|c|}{ Not Sequent (does not match text's sequencing + static) } & \\
\hline \multicolumn{3}{|c|}{ Image-language relationships } & Check \\
\hline \multicolumn{3}{|c|}{ Image dominant } & \\
\hline \multicolumn{3}{|c|}{ Language dominant } & \\
\hline \multicolumn{3}{|l|}{ Co-referential } & \\
\hline \multicolumn{3}{|l|}{ Additive } & \\
\hline \multicolumn{3}{|l|}{ Parallel } & \\
\hline \multicolumn{3}{|l|}{ Interdependent } & \\
\hline \multicolumn{3}{|c|}{ Types of Image } & Check \\
\hline \multirow{2}{*}{ Narrative } & $\begin{array}{l}\text { Character organization } \\
\text { sequence }\end{array}$ & as an event & \\
\hline & $\begin{array}{l}\text { Character organization as } \\
\text { event sequence }\end{array}$ & a problematic & \\
\hline \multirow{4}{*}{ Non-narrative } & Participant organization & & \\
\hline & Diagram & & \\
\hline & Chart & & \\
\hline & Graph & & \\
\hline \multirow{4}{*}{ Genre-specific } & Genre features & & Check \\
\hline & \multicolumn{2}{|c|}{ The goal of the text genre is achieved } & \\
\hline & \multicolumn{2}{|c|}{$\begin{array}{l}\text { The arrangement of information } \\
\text { following the structure of the text genre }\end{array}$} & \\
\hline & \multicolumn{2}{|c|}{$\begin{array}{l}\text { The images and language are related to } \\
\text { the language used in the text }\end{array}$} & \\
\hline \multicolumn{3}{|c|}{ Not genre-specific } & \\
\hline
\end{tabular}

[4] K. A. Onofrey and J. L. Theurer, 'What's a teacher to do: Suggestions for comprehension strategy instruction', Read. Teach., vol. 60, no. 7, pp. 681-684, 2007.

[5] J. Y. Park, 'A different kind of reading instruction: Using visualizing to bridge reading comprehension and critical literacy', J. Adolesc. Adult Lit., vol. 55, no. 7, pp. 629-640, 2012.

[6] G. Woolley, 'Developing reading comprehension: combining visual and verbal cognitive processes', Aust. J. Lang. Literacy, vol. 33, no. 2, p. $108,2010$.

[7] R. Hobbs, 'Improving reading comprehension by using media literacy activities', Voices from Middle, vol. 8, no. 4, p. 44, 2001.

[8] J. A. Livingston, 'Metacognition: An overview. Retrieved November 11, 2006'. 1997.

[9] M. W. Matlin, 'Cognition. Ganaseo'. New York: Harcourt Brace College Publisher, 1998.

[10] U. Mulbar, 'Metakognisi Siswa Dalam Menyelesaikan Masalah Matematika', Tersedia pada http//www. usmanmulbar. files. wordpress. com. Diakses pada, vol. 8, 2008.

[11] Tacassu Project, 'Metacognition', http://www.hku.hk/cepc/taccasu/ref/metacognition, 2008. .

[12] M. Macken-Horarik, 'Something to shoot for": A systemic functional approach to teaching genre in secondary school science', Genre Classr. Mult. Perspect., pp. 17-42, 2002.

[13] A. S. Palincsar, 'Collaborative approaches to comprehension instruction', Rethink. Read. Compr., pp. 99-114, 2003.

[14] J. R. Martin, 'Genre and language learning: A social semiotic perspective', Linguist. Educ., vol. 20, no. 1, pp. 10-21, 2009.

[15] F. Serafini, 'Expanding perspectives for comprehending visual images in multimodal texts', J. Adolesc. Adult Lit., vol. 54, no. 5, pp. 342-350, 2011.

[16] J. Rowsell and A. Burke, 'Reading by design: Two case studies of digital reading practices', J. Adolesc. Adult Lit., vol. 53, no. 2, pp. 106118, 2009.

[17] G. R. Kress and T. Van Leeuwen, Reading images: The grammar of visual design. Psychology Press, 1996.

[18] L. Unsworth and E. Chan, 'Bridging multimodal literacies and national assessment programs in literacy', Aust. J. Lang. Literacy, vol. 32, no. 3, p. 245, 2009.

[19] E. Chan and L. Unsworth, 'Image-language interaction in online reading environments: challenges for students' reading comprehension', Aust. Educ. Res., vol. 38, no. 2, p. 181, 2011. 